\title{
Multidimensional Testing of Thermal Protection Materials in the Arcjet Test Facility
}

\author{
Parul Agrawal \\ ELORET Corporation, Sunnyvale, CA 94087
}

\author{
Donald T. Ellerby ${ }^{\dagger}$, Mathew R. Switzer ${ }^{\ddagger}$, Thomas H. Squire ${ }^{\S}$ \\ NASA Ames Research Center, Moffett Field, CA 94035-1000
}

\begin{abstract}
Many thermal protection system materials used for spacecraft heatshields have anisotropic thermal properties, causing them to display significantly different thermal characteristics in different directions, when subjected to a heating environment during flight or arcjet tests. The anisotropic effects are enhanced in the presence of sidewall heating. This paper investigates the effects of anisotropic thermal properties of thermal protection materials coupled with sidewall heating in the arcjet environment. Phenolic Impregnated Carbon Ablator (PICA) and LI-2200 materials (the insulation material of Shuttle tiles) were used for this study. First, conduction-based thermal response simulations were carried out, using the Marc.Mentat finite element solver, to study the effects of sidewall heating on PICA arcjet coupons. The simulation showed that sidewall heating plays a significant role in thermal response of these models. Arcjet tests at the Aerodynamic Heating Facility (AHF) at NASA Ames Research Center were performed later on instrumented coupons to obtain temperature history at sidewall and various radial locations. The details of instrumentation and experimental technique are the prime focus of this paper. The results obtained from testing confirmed that sidewall heating plays a significant role in thermal response of these models. The test results were later used to validate the two-dimensional ablation, thermal response, and sizing program, TITAN. The test data and model predictions were found to be in excellent agreement.
\end{abstract}

\section{Introduction}

A rcjet tests are performed to investigate the thermal response of TPS materials at very high heat flux and entry-like atmospheric pressure. The tests are conducted in the aero thermal facilities that produce high enthalpy hypersonic flows, with the help of powerful arc heaters. ${ }^{1}$ The tests are also used to provide experimental data to develop and validate thermal response modeling of TPS materials. ${ }^{2,3}$ The coupons used for the validation of thermal response models are usually axisymmetric, with an Iso-Q shape (defined in Section II), to provide uniform heat flux at the stagnation surface. They are instrumented with centerline thermocouples to measure temperature history during the high temperature plasma exposure and cooldown period afterwards. Optical pyrometers are also used to obtain the surface temperature at the stagnation point. To validate the response models, thermocouple and pyrometer data are compared against the numerically predicted thermal response. Historically, the thermal response

\footnotetext{
* Senior Research Scientist, NASA Ames Research Center, Thermal Protection Materials and Systems Branch, MS 234-1, Moffett Field, CA 94035, (650)-604-3764, AIAA Member

${ }^{\dagger}$ Materials Research Engineer, NASA Ames Research Center, Thermal Protection Materials and Systems Branch, MS 234-1, Moffett Field, Moffett Field, CA 94035, (650)-604-2811.

${ }^{*}$ Materials Engineer, NASA Ames Research Center, Thermal Protection Materials and Systems Branch, MS 242-6, Moffett Field, CA 94035, (650)-604-4741.

$\S$ Aerospace Engineer, NASA Ames Research Center, Thermal Protection Materials and Systems Branch, MS 234-1, Moffett Field, CA 94035, (650)-604-1113, AIAA Member.
} 
modeling codes used for heatshield design and sizing are based on one-dimensional governing equations. Therefore, for validation purposes, it is assumed that the centerline thermocouple data represents one-dimensional heating conditions. ${ }^{4}$ However, the computational fluid dynamic predictions show that the cylindrical sidewall of an arcjet test coupon that is exposed to a heating environment could receive up to $10-13 \%$ of stagnation point heat flux..$^{5}$ If an anisotropic material has significantly different thermal conductivity in different directions through the material, the effects of sidewall heating become very prominent and the one-dimensional assumptions are not valid. Energy entering from the cylindrical surface of the sample may conduct more rapidly towards the center of the model than would the same amount of energy entering from the stagnation surface. Even for a short test, charring from sidewall heating can become significant as shown in Figure 1. For TPS materials like PICA, ${ }^{6}$ which is transverse isotropic with significantly higher conductivity in-plane than thru-the-thickness, the one-dimensional response models usually underpredict the centerline temperature rise. ${ }^{5}$ Therefore, it is important to investigate the extent of sidewall heating and its effects on the material coupons.

A parametric two-dimensional transient finite element analysis was performed on an idealized arcjet model exposed to sidewall heat flux along with the front surface heat flux. The model was based on pure thermal conduction and did not include pyrolysis or ablation. The purpose of these analyses was to assess the relative effect of sidewall heating on the temperature response at the centerline of the PICA sample. The details are provided in Section 2. Special tests were then designed and conducted at the Aerodynamic Heating Facility (AHF) at NASA Ames Arcjet Complex to assess the magnitude of sidewall heating and its effect on temperature history of the materials. The coupons made of PICA and LI- $2200^{7}$ were instrumented with thermocouples at various off-axis radial locations at different depths from the stagnation point. The facility description, design, and fabrication details of the test coupons are provided in the later sections of this paper.

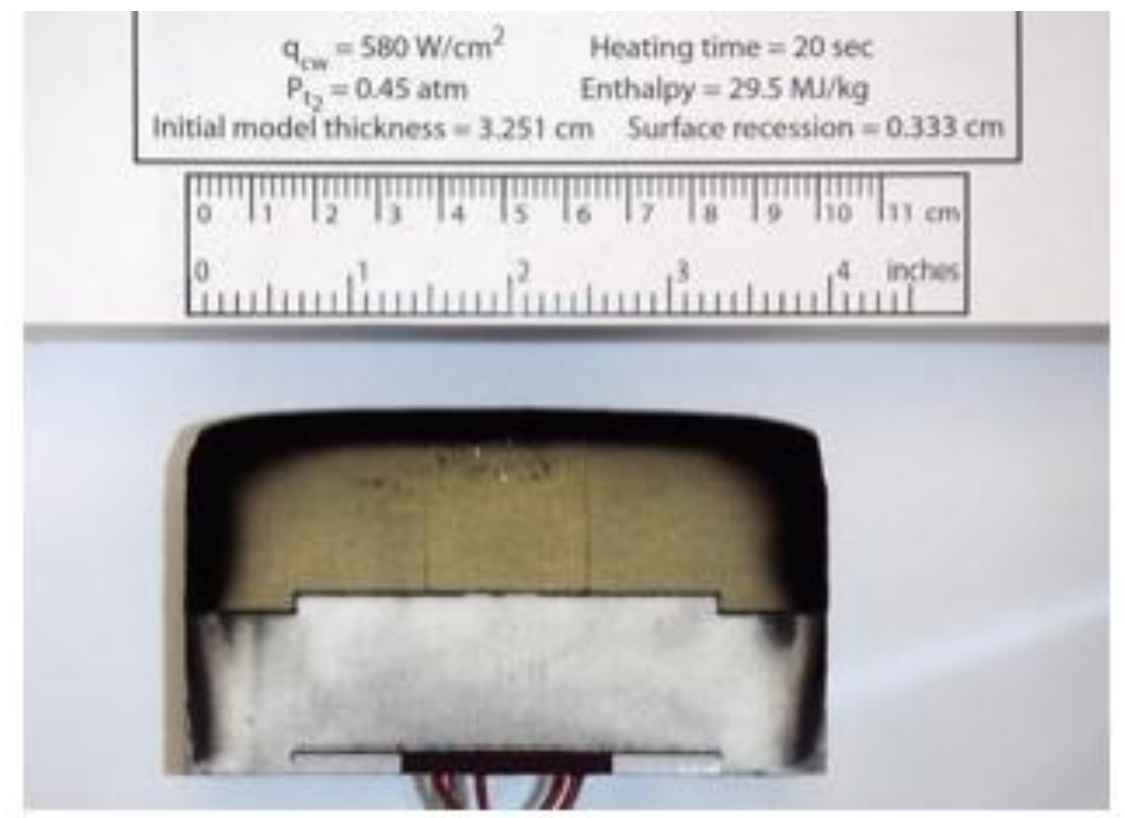

Figure 1. PICA coupon after arcjet test.

\section{Analysis Model Development and Results}

The finite element (FE) analyses were performed with the MSC.Marc commercial finite element package. MSC.Marc supports fully transient, non-linear, coupled thermal/mechanical FE analyses. ${ }^{8}$ The model geometry was created to replicate the arc-jet test coupons and is shown in Figure 2. It is axisymmetric with a $5.08 \mathrm{~cm}$ radius and $9.36 \mathrm{~cm}$ height. The $10.16 \mathrm{~cm}$ radius curvature on the forward face is meant to approximate an Iso-Q surface. That is, under arcjet heating conditions, the forward surface of the model should experience nearly uniform heat flux. This assumption was used in the application of the heating boundary conditions. Only the PICA part of arc-jet coupon was included in the finite element analysis model. The back face of the sample, which would actually be attached to the test fixture, was assumed to be adiabatic. The finite element model took advantage of the axisymmetric nature of the 
geometry and heating conditions and was created using 2-D axisymmetric elements. The model was constructed of a mesh of 8-noded quadrilateral elements with bi-quadratic interpolation functions. The axis of symmetry is along the X-coordinate. The model consisted of approximately 15000 nodes and 4900 elements. The thermal properties were based on recent measurements of PICA properties from the Crew Exploration Vehicle TPS Advanced Development Project (CEV TPS ADP). ${ }^{9}$

The measured thermal conductivity of PICA showed a strong directional dependence. In order to accommodate the expected temperature range in the analyses, the conductivity curves were extrapolated to temperatures higher than the material would be realistically expected to operate. Pyrolysis and ablation of PICA were not modeled in the conduction analyses. The purpose of the parametric analyses was to evaluate the relative influence of the sidewall heating on the thermal response of the model. The predicted temperatures at the stagnation point did not accurately represent the actual temperature during arcjet tests. A constant heat flux of $580 \mathrm{~W} / \mathrm{cm}^{2}\left(511 \mathrm{Btu} / \mathrm{ft}^{2}\right.$-s $) \mathrm{was}$ applied to the forward surface of the model. The heat flux at the rounded corner was assumed to vary linearly with stream length from the peak value to the sidewall value. The heat flux on the lateral sidewall of the model was varied parametrically as a percentage of the stagnation value, for $0 \%, 2 \%, 5 \%$, and $10 \%$. The forward surface, corner, and sidewall were also allowed to re-radiate to the environment, which was at a room temperature of $21^{\circ} \mathrm{C}(294 \mathrm{~K})$. The back face of the model was adiabatic. The entire model was initially set to room temperature. During the transient analyses, the heat flux was linearly increased from zero to the peak value over a period of one second. This "start up" period helped mitigate the transient artifacts in the solution. The total heating time was also varied parametrically for 15 seconds, 30 seconds, and 60 seconds. After the heat pulse, the model was allowed to cool down, through radiation to the environment, for 500 seconds.

The temperature history results at two centerline locations in the model were compared with one another. The two locations were $2.54 \mathrm{~cm}$ and $5.08 \mathrm{~cm}$ distance along the center line from the stagnation point. Figure 3 and Figure 4 show the temperature history curves of the in-depth response for the 15- and 60-second heat exposure, respectively. Each figure includes the four different sidewall-heating levels. The $0 \%$ sidewall heating case would be closest to representing a pure 1-D conduction condition with energy entering the model only from the forward surface. The existence of the sidewall heating, even at $2 \%$ of the stagnation value, had a significant effect on the centerline thermal response at both in-depth locations for all heating conditions. For any given heating condition, the 2-D effect was most pronounced at the $5.08 \mathrm{~cm}$ location. The sidewall heating not only increased the peak temperature at the in-depth locations, but it also shifted the time that the peak temperature occurred. Closer to the surface, at the $2.54 \mathrm{~cm}$ depth location, the time-to-peak temperature increased as the sidewall heating increased. Further in depth, at the $5.08 \mathrm{~cm}$ location, the time-to-peak temperature decreased as the sidewall heating increased. At the $2.54 \mathrm{~cm}$ deep location, the effect of the sidewall heating was clearly apparent after about 100 seconds. At the $5.08 \mathrm{~cm}$ deep location, the effect was apparent after only about 50 seconds. In fact, at the $5.08 \mathrm{~cm}$ location for the 15-second exposure, the rise in temperature was due as much to sidewall heating as to the stagnation surface heating, even for the $2 \%$ case. This supports the scientific intuition that the further in depth a point is, the more pronounced are the 2-D effects.

Figure 5 shows the temperature contours for the 15-second heating pulse case for all four of the sidewall heating conditions: $0 \%, 2 \%, 5 \%$, and $10 \%$. The contours clearly show the large differences in temperature distributions that develop with increasing sidewall heating. Figure 6 shows the peak temperature at the two in-depth locations as a function of the sidewall heating. These analyses clearly show the relative effect of 2-D conduction on the thermal response at the centerline of a PICA arcjet model. The results indicate that for a $10.16 \mathrm{~cm}$ diameter PICA arcjet model, centerline temperatures are influenced by multidimensional heat conduction from the sidewall at depths of about $2.54 \mathrm{~cm}$ or greater, or at times of about 100 seconds or greater. In general, the further in depth from the stagnation surface, the sooner the multidimensional effects become apparent and the larger they grow in magnitude. This study made a compelling case to investigate further and conduct arcjet tests to measure the sidewall temperature and obtain off-axis thermal response for PICA coupons. The next few sections describe the model fabrication and arcjet test results. 


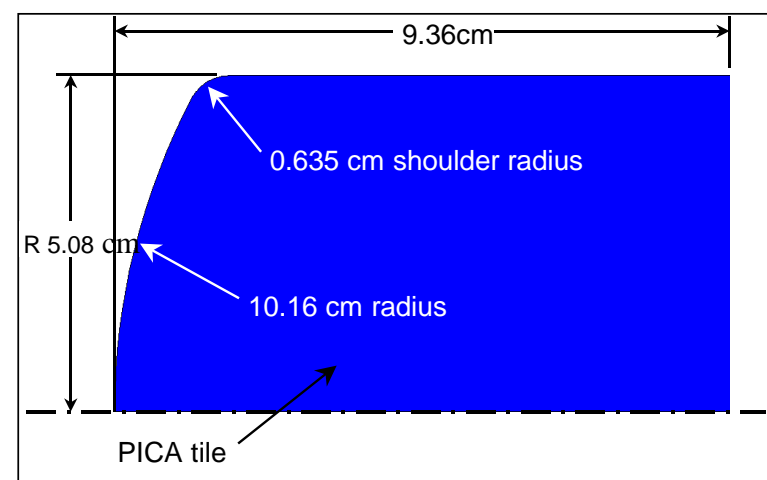

Figure 2. Arcjet model geometry for finite element analysis.

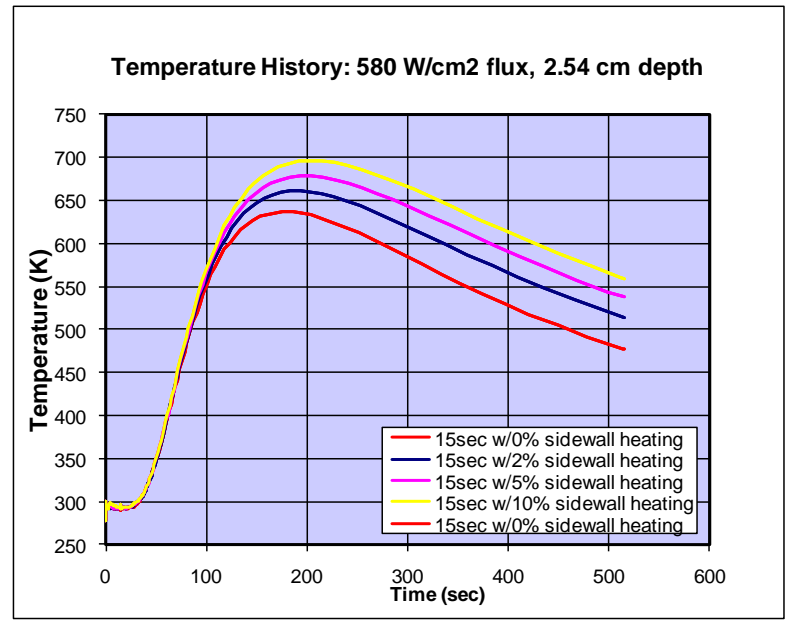

a) $2.54 \mathrm{~cm}$ depth

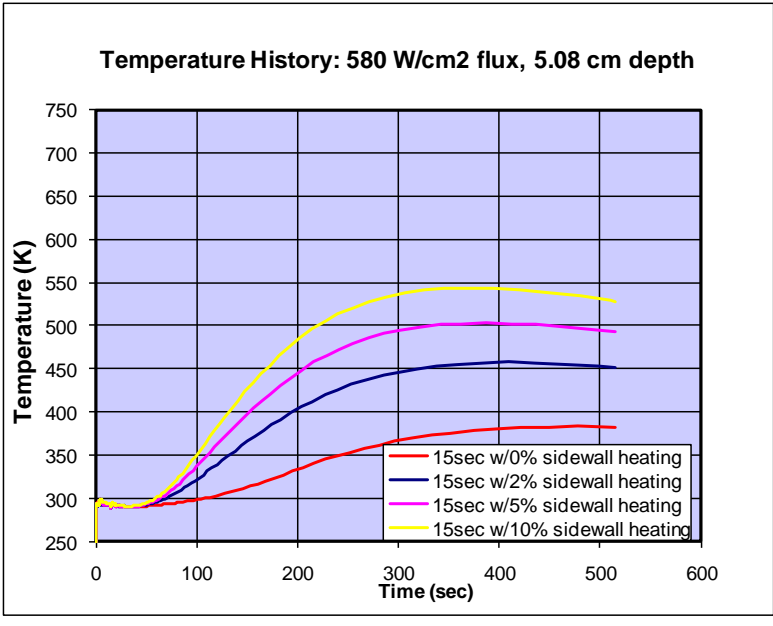

b) $5.08 \mathrm{~cm}$ depth

Figure 3. In-depth temperature history for 15 -second heat pulse at $580 \mathrm{~W} / \mathrm{cm}^{2}$ magnitude.

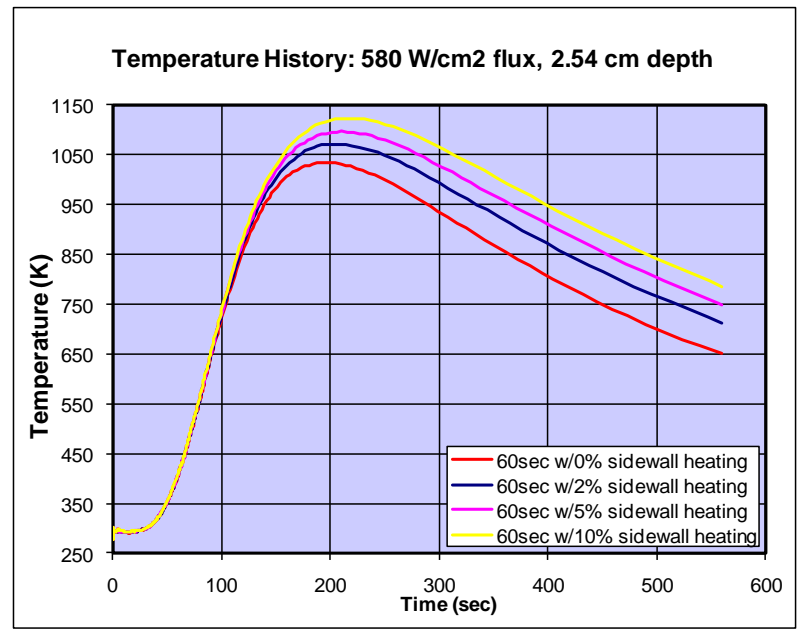

a) $2.54 \mathrm{~cm}$ depth

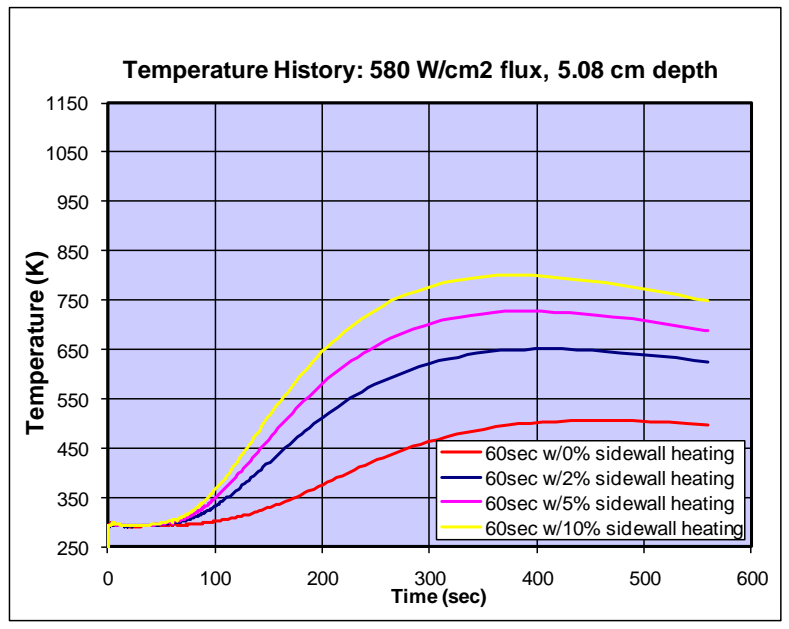

b) $5.08 \mathrm{~cm}$ depth

Figure 4. In-depth temperature history for 60 second heat pulse at $580 \mathrm{~W} / \mathrm{cm}^{2}$ magnitude. 


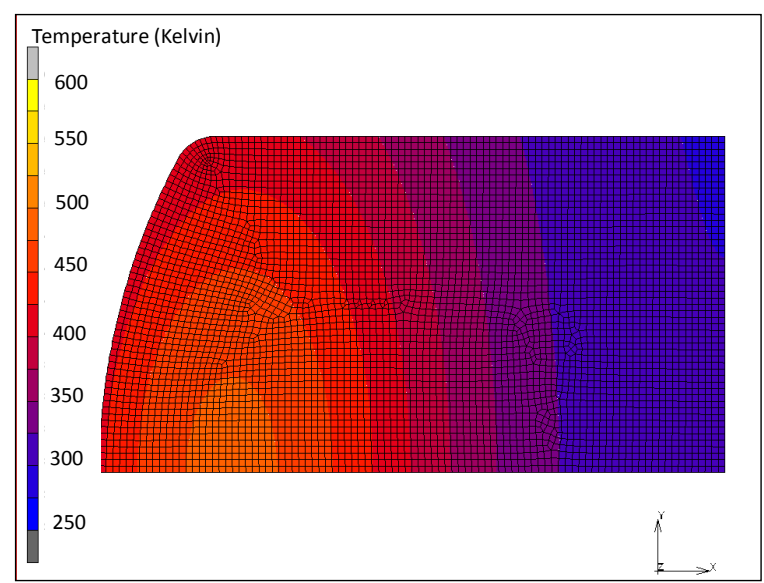

a) $0 \%$ sidewall heating

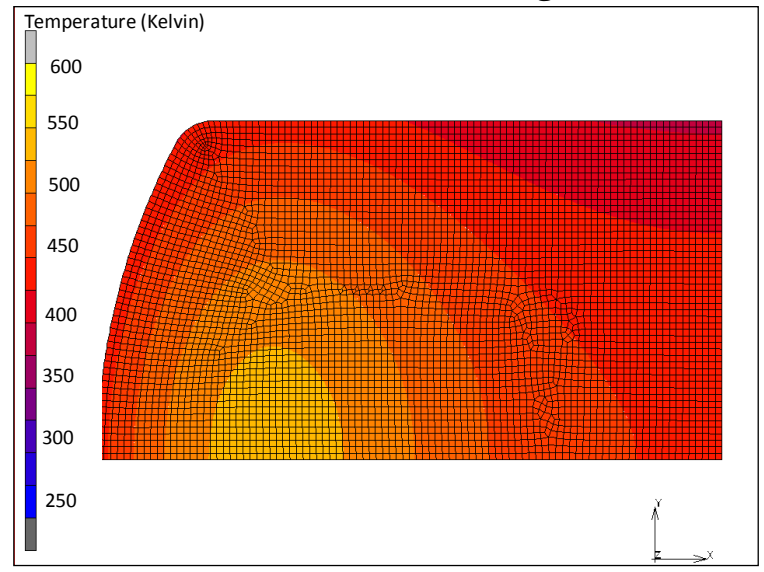

c) $5 \%$ sidewall heating

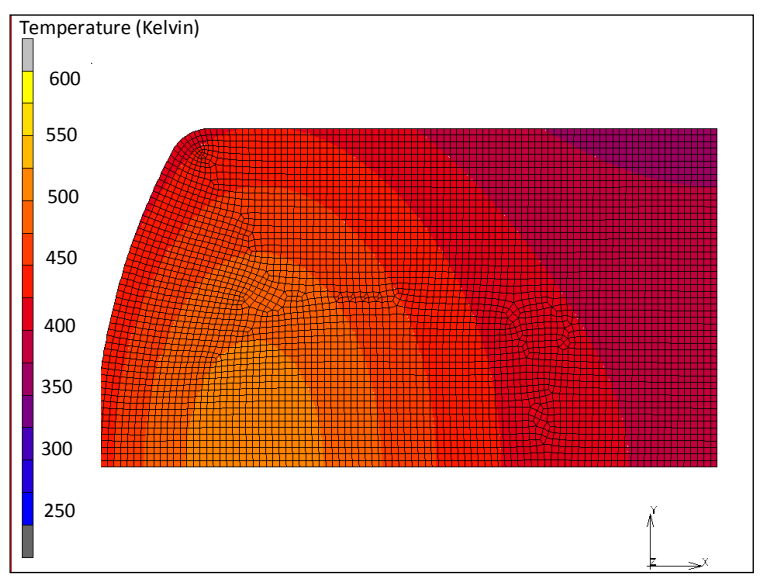

b) $2 \%$ sidewall heating

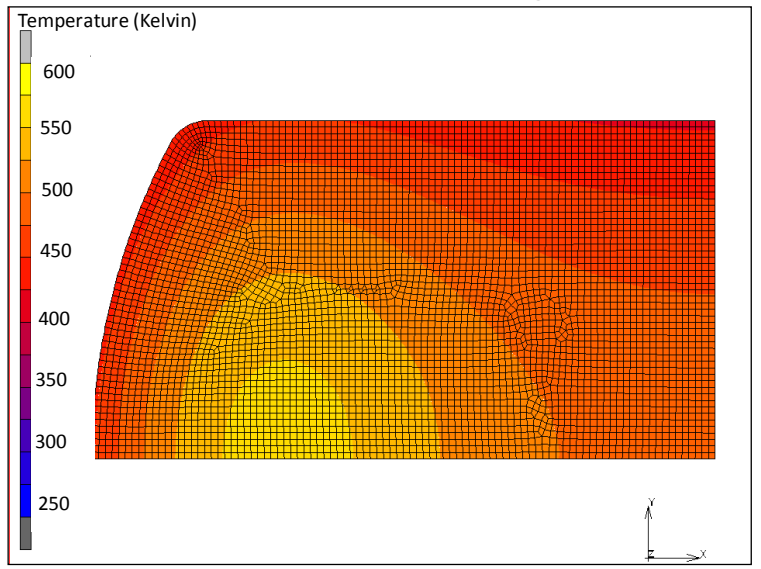

d) $10 \%$ sidewall heating

Figure 5. Temperature contours $(\mathrm{K})$ at 515 seconds.

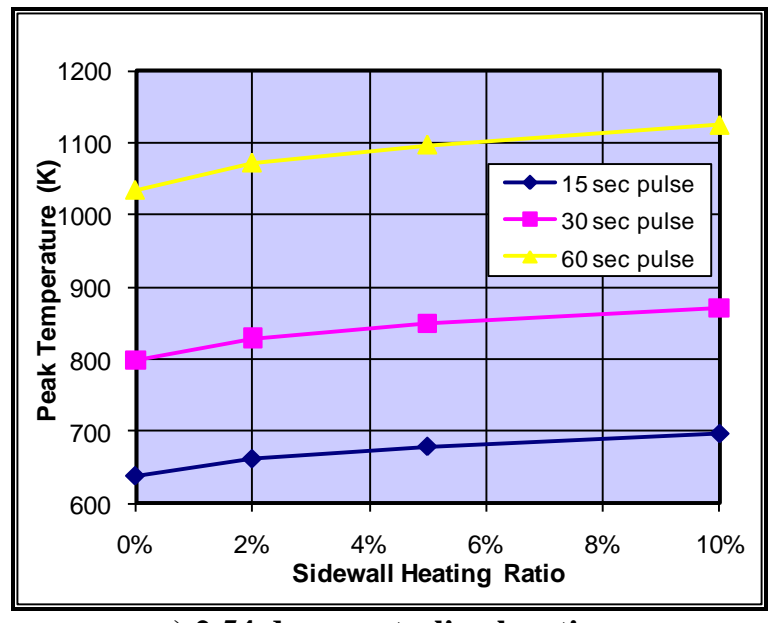

a) 2.54 deep centerline location



b) $5.08 \mathrm{~cm}$ deep centerline location

Figure 6. Peak in-depth temperature for various sidewall heating ratio compared to stagnation heat flux 


\section{Test Article Design, Fabrication, and Instrumentation}

The articles for arc-jet tests were designed to address the two objectives. The first was to compare the relative magnitude of sidewall heating with that of the fore body (front surface) by obtaining the temperature profile at sidewall. The second objective was to investigate the effect of sidewall heating coupled with thermal anisotropy on PICA. For sidewall heating experiment LI-2200 coupons were fabricated as this is a well characterized material. The thermocouples were installed on the stagnation point and at various locations at sidewall, beneath the RCG coating on LI-2200 coupons. These coupons were used to obtain temperature history at various locations on the cylindrical sidewall in order to validate the CFD predictions of sidewall heating. For the second objective, we designed PICA samples with centerline and off-axis thermocouples at various depths. These coupons were used for validation of the multidimensional thermal response model. Standard PICA coupons with centerline thermocouples only served as a control for comparison to the temperature history of centerline thermocouples from PICA coupons that had off-axis thermocouples along with centerline thermocouples. The second category of samples were made of LI-2200 material with thermocouples on the stagnation point and at various heights from the stagnation point at the sidewall surface. A summary of all the test articles is provided in Table 1.

\section{A. LI-2200 Coupon Dimensions and Model Design}

The LI-2200 samples were designed to get an accurate surface temperature measurement from the front face and sidewall. The objective was to obtain sidewall heating rates for comparison with CFD predictions. These coupons were $10.16 \mathrm{~cm}$ in diameter with an Iso-Q shape at the front face to ensure uniform heat flux. The model height, without the holder, was $5.08 \mathrm{~cm}$. The samples and holders were made of LI-2200. The overall height of the model including the holder was $10.16 \mathrm{~cm}$. These samples were coated with Reaction-Cured Glass (RCG) on the top and at the sidewall to restrain the flow of hot gases inside LI-2200 coupons and provide higher emissivity for radiation equilibrium. Thermocouples were embedded below the surface coating. There was one thermocouple mounted at the stagnation point and the other five thermocouples were located at the sidewall surface at different distances from the stagnation point. Figure 7 shows X-ray scans of the sample with embedded thermocouples. The actual depths and radial locations of these thermocouples are listed in Table 2.

\section{B. PICA Coupons Dimensions and Model Design}

A novel design and instrumentation approach was developed at NASA Ames Research Center to fabricate the PICA test coupons with embedded off-axis and centerline thermocouples. The model was fabricated with internal lobes containing the off-axis thermocouples, centerline plug and the LI-2200 holder at the base. The overall coupon height at the stagnation point was $4.128 \mathrm{~cm}$ and the diameter was $10.16 \mathrm{~cm}$. The front stagnation face was designed and cut according to the Iso-Q geometry to ensure uniform heat flux. The off-axis thermocouples were installed using a three-lobed cloverleaf-shaped architecture encapsulating the centerline plug. These lobes were fabricated to provide different radial locations away from centerline. Two of these cloverleaf inserts were laid on top of each other and inserted on the outer PICA shell. The lobes were separated by a $120^{\circ}$ angle. The lobes on the top insert were of different size, so that thermocouples could be mounted at different radial locations. On the bottom insert, all three lobes were of the same size, positioning all thermocouples at the same radius to be separated by a $120^{\circ}$ angle. The objective behind this design was to investigate the azimuthal symmetry of heat flux and temperature distributions. The analysis results showed that at the farthest distance from the center stagnation point, the effects of sidewall heating are more pronounced. Therefore, the lobes were design to provide significant distance between the center stagnation point and the off-axis thermocouple. A cylindrical plug, embedded with thermocouples along the centerline at different locations, was inserted through the center of the inserts. Both the centerline cylindrical plug and three-lobed inserts were made of PICA. A LI-2200 holder was bonded to the base of the model.

The assembly sequence and picture of the model are shown in Figure 8 and Figure 9. X-ray scans were taken for all the coupons to ensure correct thermocouple installation and to allow accurate measurement of their locations inside each coupon. The top and side views of X-ray images of the coupon, showing various thermocouple locations, are shown in Figure $10 \mathrm{~A}$ and B, respectively. It can be clearly seen from the images that the thermocouples were azimuthally equidistant. Figure 11 shows the map of thermocouples (TC) for these samples. Nominal thermocouple locations and their types are listed in Table 2.

PICA coupons, instrumented only with centerline thermocouple plugs, were used as controls for this test series. The locations of thermocouples on control PICA coupons are also listed in Table 2. These coupons were fabricated at Boeing. The thickness for control coupons at the stagnation point was $3.5 \mathrm{~cm}$. 
Table 1. Description of test articles

\begin{tabular}{|c|c|c|c|c|c|}
\hline Material & Objective & $\begin{array}{l}\text { Diameter } \\
(\mathbf{c m})\end{array}$ & $\begin{array}{l}\text { Coupons height at } \\
\text { stagnation point } \\
(\mathbf{c m})\end{array}$ & Coating & $\begin{array}{l}\text { Model } \\
\text { Instrumentation } \\
\text { (Themocouples) }\end{array}$ \\
\hline LI-2200 & $\begin{array}{c}\text { CFD validation, } \\
\text { sidewall heating }\end{array}$ & $\begin{array}{c}10.16 \\
\text { Iso-Q }\end{array}$ & 5.08 & RCG & 6 R-type \\
\hline PICA & $\begin{array}{c}\text { Thermal Response } \\
\text { Model, control }\end{array}$ & $\begin{array}{c}10.16 \\
\text { Iso-Q }\end{array}$ & 3.5 & No & 2 R-type, 3 K-type \\
\hline PICA & $\begin{array}{c}\text { Thermal Response } \\
\text { Model, off-axis } \\
\text { measurements }\end{array}$ & $\begin{array}{c}10.16 \\
\text { Iso-Q }\end{array}$ & 4.128 & No & 1 R-type, 8 K-type \\
\hline
\end{tabular}

Table 2. Thermocouple depths and radial locations for test models

\begin{tabular}{|c|c|c|c|c|c|c|c|c|c|c|}
\hline Model Type & & $\mathrm{TC1}$ & TC2 & TC3 & TC4 & TC5 & TC6 & TC7 & TC8 & TC9 \\
\hline & $\begin{array}{l}\text { Depth from } \\
\text { Stagnation point } \\
(\mathrm{cm}) \\
\end{array}$ & 0.38 & 0.76 & 1.14 & 1.52 & 3.05 & $\mathrm{~N} / \mathrm{A}$ & $\mathrm{N} / \mathrm{A}$ & $\mathrm{N} / \mathrm{A}$ & $\mathrm{N} / \mathrm{A}$ \\
\hline PICA Control & \begin{tabular}{|l} 
Radial length \\
from center $(\mathrm{cm})$
\end{tabular} & 0.00 & 0.0 & 0.0 & 0.0 & 0.0 & $\mathrm{~N} / \mathrm{A}$ & $\mathrm{N} / \mathrm{A}$ & $\mathrm{N} / \mathrm{A}$ & $\mathrm{N} / \mathrm{A}$ \\
\hline \multirow[b]{2}{*}{$\begin{array}{l}\text { PICA-off axis } \\
\text { coupon }\end{array}$} & $\begin{array}{l}\text { Depth from } \\
\text { Stagnation point } \\
(\mathrm{cm}) \\
\end{array}$ & 0.76 & 2.29 & 3.05 & 2.29 & 2.29 & 2.29 & 3.05 & 3.05 & 3.05 \\
\hline & $\begin{array}{l}\text { Radial length } \\
\text { from center }(\mathrm{cm})\end{array}$ & 0.00 & 0.00 & 0.00 & 4.45 & 3.81 & 2.54 & 4.45 & 4.45 & 4.45 \\
\hline \multirow[b]{2}{*}{ LI-2200 } & $\begin{array}{l}\text { Depth from } \\
\text { Stagnation point } \\
(\mathrm{cm})\end{array}$ & 0.00 & 1.62 & 2.29 & 3.05 & 3.81 & $\begin{array}{c}\text { 3.05(on } \\
\text { sidewall } \\
180 \text { deg } \\
\text { from TC-4) }\end{array}$ & $\mathrm{N} / \mathrm{A}$ & $\mathrm{N} / \mathrm{A}$ & $\mathrm{N} / \mathrm{A}$ \\
\hline & \begin{tabular}{|l} 
Radial length \\
from center $(\mathrm{cm})$
\end{tabular} & 0.00 & 5.08 & 5.08 & 5.08 & 5.08 & 2.00 & $\mathrm{~N} / \mathrm{A}$ & $\mathrm{N} / \mathrm{A}$ & $\mathrm{N} / \mathrm{A}$ \\
\hline
\end{tabular}

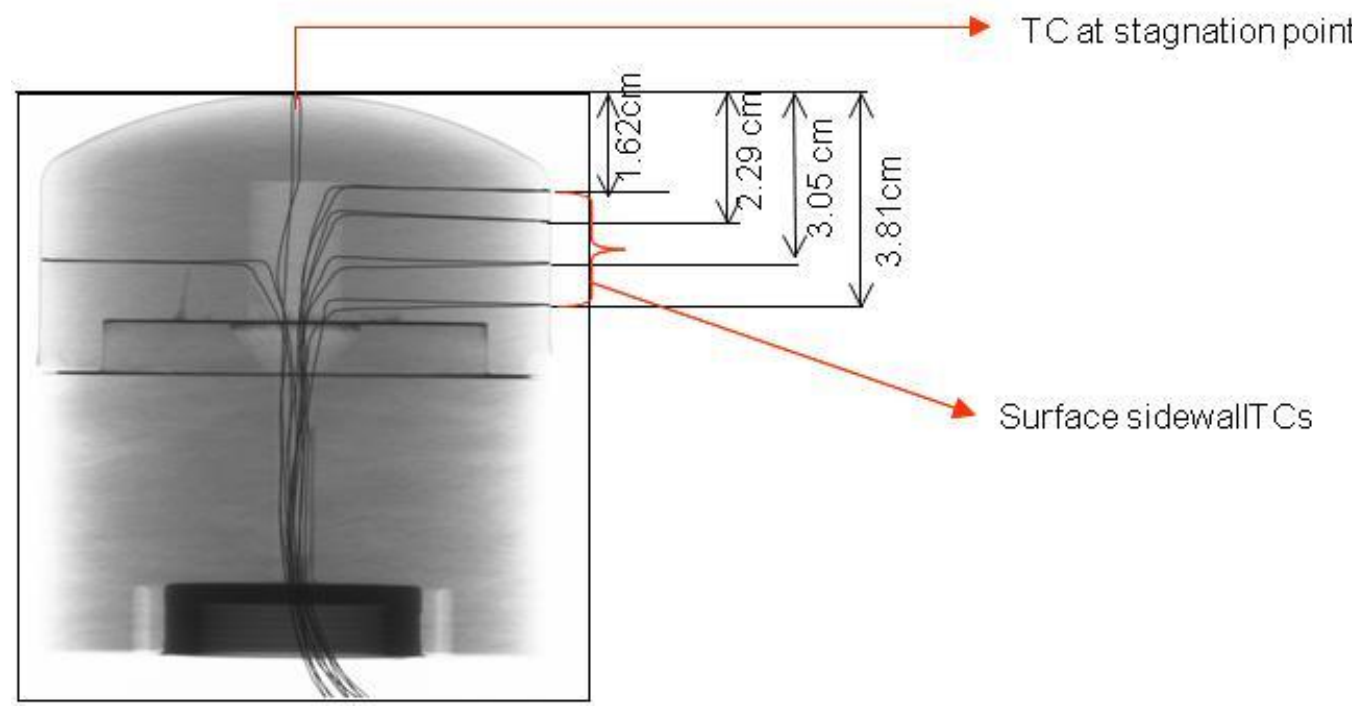

Figure 7. X-ray image of LI-2200 Coupon 


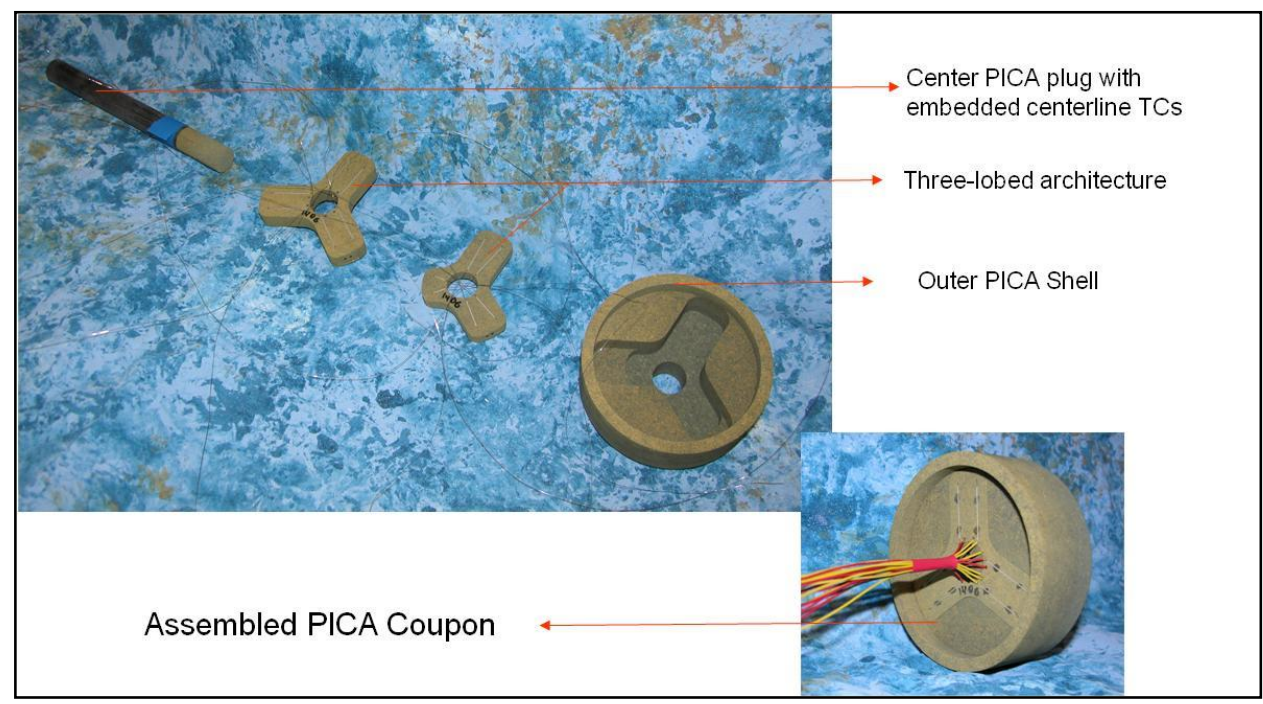

Figure 8. Assembly sequence of off-axis PICA coupons

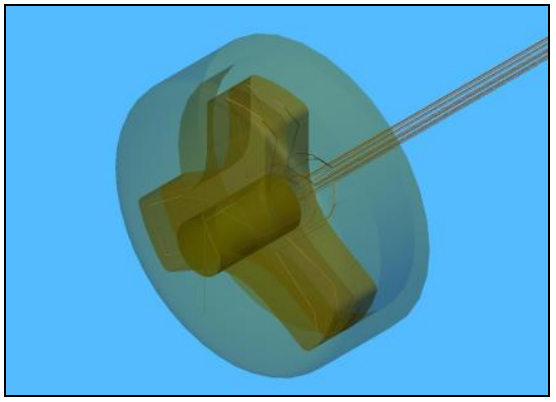

Figure 9. Drawing of PICS coupon showing the lobes and centerline plugs inserted inside the outer shell.
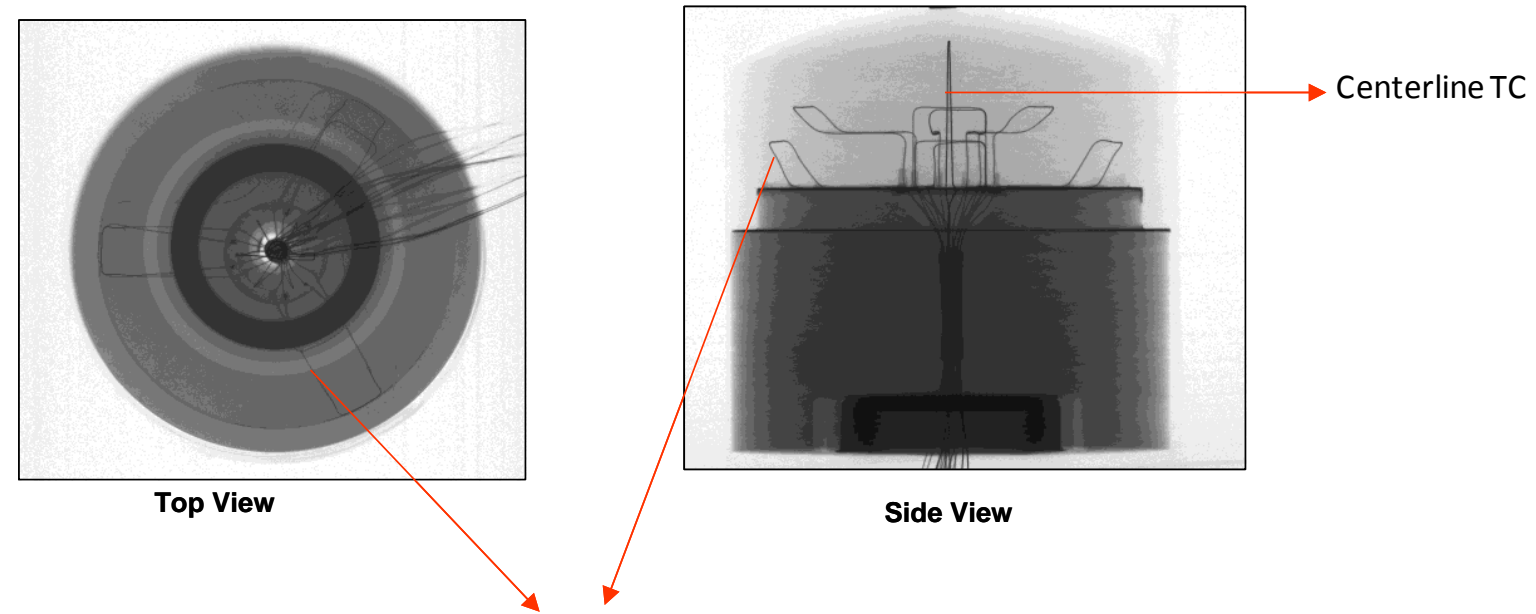

Off-axis TCs

Figure 10. X-ray image of Off-axis PICA Coupons 


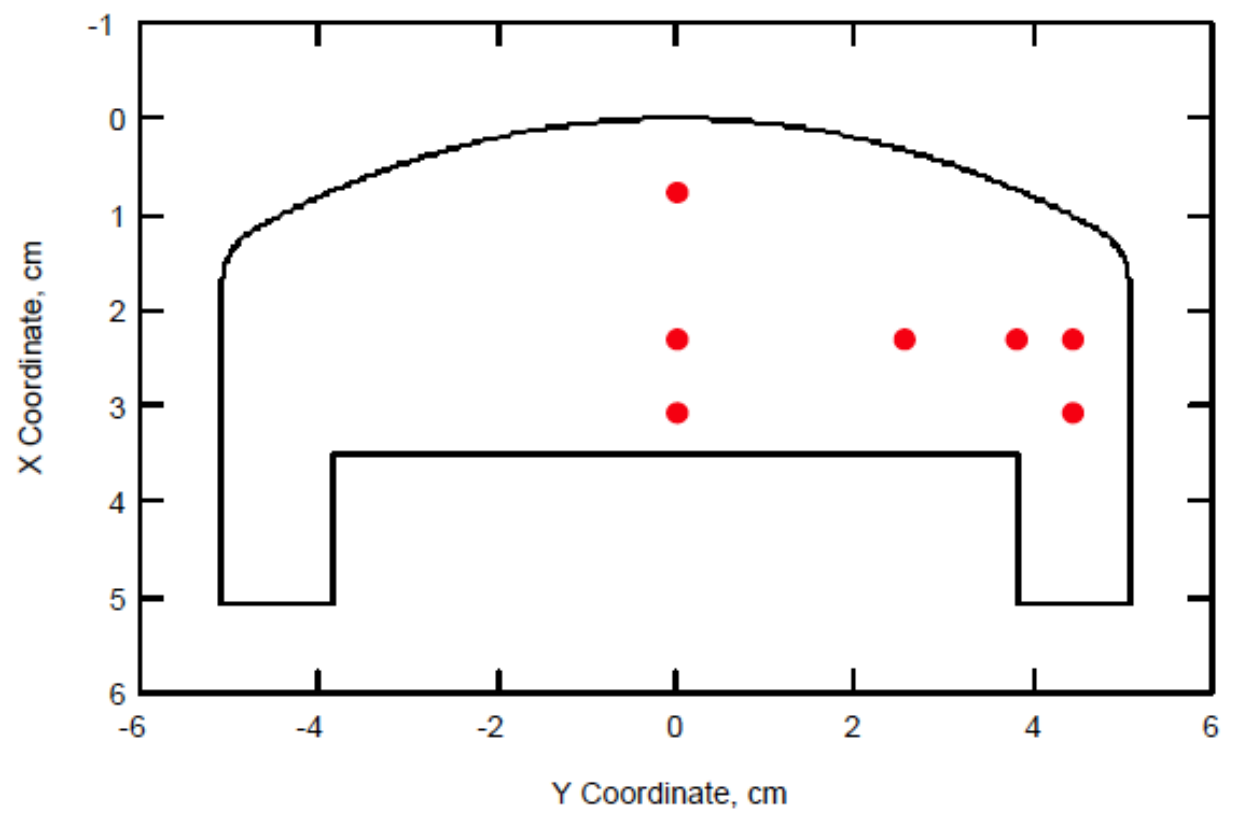

Figure 11. Thermocouple map for off-axis PICA coupons

\section{Test facility and Environment Description}

The tests were conducted at the Aerodynamic Heating Facility (AHF) located at NASA Ames Research Center. It is a flexible arcjet facility that operates with 20-megawatt arc heaters and conical nozzles. The arc heater operates at pressures from 1.0 to 10.0 atm and enthalpy levels from $11.0 \mathrm{MJ} / \mathrm{Kg}$ to $32.0 \mathrm{MJ} / \mathrm{Kg}$. The detailed description of the facility is provided in references 2,3 and 10 . For these tests the arc heater was coupled with a conical nozzle of $8^{\circ}$ half angle and $45.72 \mathrm{~cm}(18 \mathrm{inch})$ exit diameter. The nozzle was discharged into a $2.44 \mathrm{~m} \times 2.44 \mathrm{~m} \times 2.44 \mathrm{~m}$ walk-in test chamber. Chamber pressure was a function of mass flow and pumping rates, ranging from 0.1 to 10 torr. Samples were mounted on a carriage arm consisting of five stings. Each sting could carry one sample. There was also a swing arm for slug calorimeter measurements. The samples were exposed to the plasma flow in an open jet, formed between the nozzle exit and the entrance to the diffuser. Figure 12 shows the coupons mounted inside the test chamber. The thermocouple extensions were routed to a patch panel inside the chamber for data recording. There were ports on the sides and ceiling of the test chambers for optical pyrometers and imaging. This allowed video recording of the test articles and the plasma streams.

Two different conditions were selected after studying the AHF performance envelope and past run histories. The low heat flux conditions were chosen, as LI-2200 coupons may not survive the heat flux beyond $250 \mathrm{~W} / \mathrm{cm}^{2}$, and it was essential to obtain the temperature at the sidewalls. The test durations corresponding to $175 \mathrm{~W} / \mathrm{cm}^{2}$ and 250 $\mathrm{W} / \mathrm{cm}^{2}$ conditions were chosen to maintain identical heat loads. CFD calculations were performed for these conditions to estimate the relative sidewall heat flux compared to the stagnation point and front surface. The plots showing the heat flux on arc-jet coupons are shown in Figures 13a and 13b. The calculations show that sidewall heating is approximately $10 \%$ of the heat flux at stagnation point, a significant number for these heat flux conditions.

Table 3 summarizes the run conditions and test matrix for each condition. For each condition, one calibration run was made with calorimeters of same dimensions as that of the test models. During each calibration run a Teflon sample was also exposed to the plasma stream, with a similar exposure as the LI-2200 and PICA coupons, to ensure flow uniformity. After reviewing the calibration runs, the models were tested in subsequent runs. Table 3 provides the description of each run. In addition to thermocouples, data from optical pyrometers was also obtained for stagnation point and sidewall surface temperatures. The next section describes the test results and analytical model validation. 
Table 3. Test Environment and Coupon Description

\begin{tabular}{|c|c|c|c|c|c|c|}
\hline Run \# & Condition & $\begin{array}{l}\text { Cold Wall } \\
\text { Heat Flux } \\
(\mathrm{W} / \mathrm{cm} 2)\end{array}$ & $\begin{array}{l}\text { Pressure } \\
(\mathrm{KPa})\end{array}$ & $\begin{array}{c}\text { Stagnation } \\
\text { Enthalpy } \\
(\mathrm{MJ} / \mathrm{Kg})\end{array}$ & Sample Material & $\begin{array}{l}\text { Exposure } \\
\text { (sec) }\end{array}$ \\
\hline \multirow{4}{*}{$\begin{array}{c}1 \\
\text { (Calibration) }\end{array}$} & \multirow{4}{*}{1} & \multirow{4}{*}{174} & \multirow{4}{*}{5.03} & \multirow{4}{*}{18.16} & $\begin{array}{l}7.62 \mathrm{~cm} \mathrm{(3} \mathrm{in)} \mathrm{Hemispherical} \\
\text { slug Calorimeter }\end{array}$ & \\
\hline & & & & & $\begin{array}{l}10.16 \mathrm{~cm} \mathrm{(4} \mathrm{in)} \mathrm{ISO-Q} \\
\text { Calorimeter }\end{array}$ & \\
\hline & & & & & \begin{tabular}{|l|}
$10.16 \mathrm{~cm}(4 \mathrm{in}) \mathrm{ISO}-\mathrm{Q}$ \\
Calorimeter \\
\end{tabular} & \\
\hline & & & & & $10.16 \mathrm{~cm}(4 \mathrm{in})$ ISO-Q Teflon & 60 \\
\hline \multirow{4}{*}{$\begin{array}{c}2 \\
\text { (Calibration) }\end{array}$} & \multirow{4}{*}{2} & \multirow{4}{*}{246} & \multirow{4}{*}{8.48} & \multirow{4}{*}{20.05} & $\begin{array}{l}\text { 7.62cm (3 in) Hemispherical } \\
\text { slug Calorimeter }\end{array}$ & \\
\hline & & & & & $\begin{array}{l}10.16 \mathrm{~cm} \mathrm{(4} \mathrm{in)} \mathrm{ISO-Q} \\
\text { Calorimeter }\end{array}$ & \\
\hline & & & & & $\begin{array}{l}10.16 \mathrm{~cm} \mathrm{(4} \mathrm{in)} \mathrm{ISO-Q} \\
\text { Calorimeter }\end{array}$ & \\
\hline & & & & & $10.16 \mathrm{~cm}(4 \mathrm{in})$ ISO-Q Teflon & 42 \\
\hline \multirow{6}{*}{3} & \multirow{6}{*}{1} & \multirow{6}{*}{175} & \multirow{6}{*}{5.07} & \multirow{6}{*}{18.24} & $\begin{array}{l}\text { 7.62cm (3 in) Hemispherical } \\
\text { slug Calorimeter }\end{array}$ & \\
\hline & & & & & $\begin{array}{l}10.16 \mathrm{~cm} \mathrm{(4} \mathrm{in)} \mathrm{ISO-Q} \\
\text { Calorimeter }\end{array}$ & \\
\hline & & & & & \begin{tabular}{|l|}
$10.16 \mathrm{~cm}(4 \mathrm{in})$ ISO-Q PICA \\
Control \\
\end{tabular} & 60 \\
\hline & & & & & $\begin{array}{l}10.16 \mathrm{~cm}(4 \mathrm{in}) \text { ISO-Q LI-2200 } \\
\text { model with Sidewall TCs }\end{array}$ & 60 \\
\hline & & & & & \begin{tabular}{|l|}
$10.16 \mathrm{~cm}(4 \mathrm{in})$ ISO-Q PICA \\
with off-axis TCs - Model 1 \\
\end{tabular} & 60 \\
\hline & & & & & $\begin{array}{l}10.16 \mathrm{~cm}(4 \mathrm{in}) \text { ISO-Q PICA } \\
\text { with off-axis TCs - Model } 2\end{array}$ & 60 \\
\hline \multirow{6}{*}{4} & \multirow{6}{*}{2} & \multirow{6}{*}{248} & \multirow{6}{*}{8.48} & \multirow{6}{*}{20.18} & $\begin{array}{l}\text { 7.62cm (3 in) Hemispherical } \\
\text { slug Calorimeter }\end{array}$ & \\
\hline & & & & & $\begin{array}{l}10.16 \mathrm{~cm} \mathrm{(4} \mathrm{in)} \mathrm{ISO-Q} \\
\text { Calorimeter }\end{array}$ & \\
\hline & & & & & $\begin{array}{l}10.16 \mathrm{~cm}(4 \mathrm{in}) \text { ISO-Q PICA } \\
\text { Control }\end{array}$ & 42 \\
\hline & & & & & $\begin{array}{l}10.16 \mathrm{~cm}(4 \mathrm{in}) \text { ISO-Q LI-2200 } \\
\text { model with Sidewall TCs }\end{array}$ & 42 \\
\hline & & & & & $\begin{array}{l}10.16 \mathrm{~cm}(4 \mathrm{in}) \text { ISO-Q PICA } \\
\text { with off-axis TCs - Model } 1 \\
\end{array}$ & 42 \\
\hline & & & & & $\begin{array}{l}10.16 \mathrm{~cm}(4 \mathrm{in}) \text { ISO-Q PICA } \\
\text { with off-axis TCs - Model } 2\end{array}$ & 42 \\
\hline
\end{tabular}




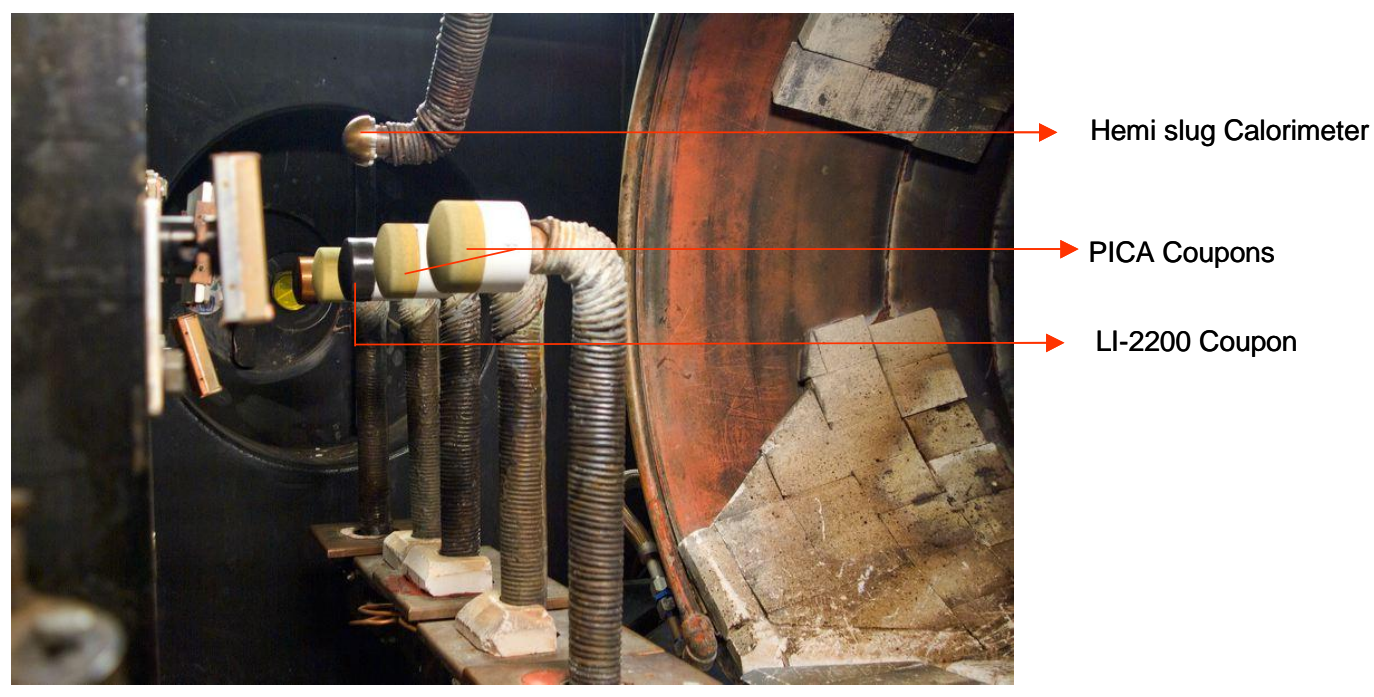

Figure 12. Coupons mounted inside the arcjet test chamber
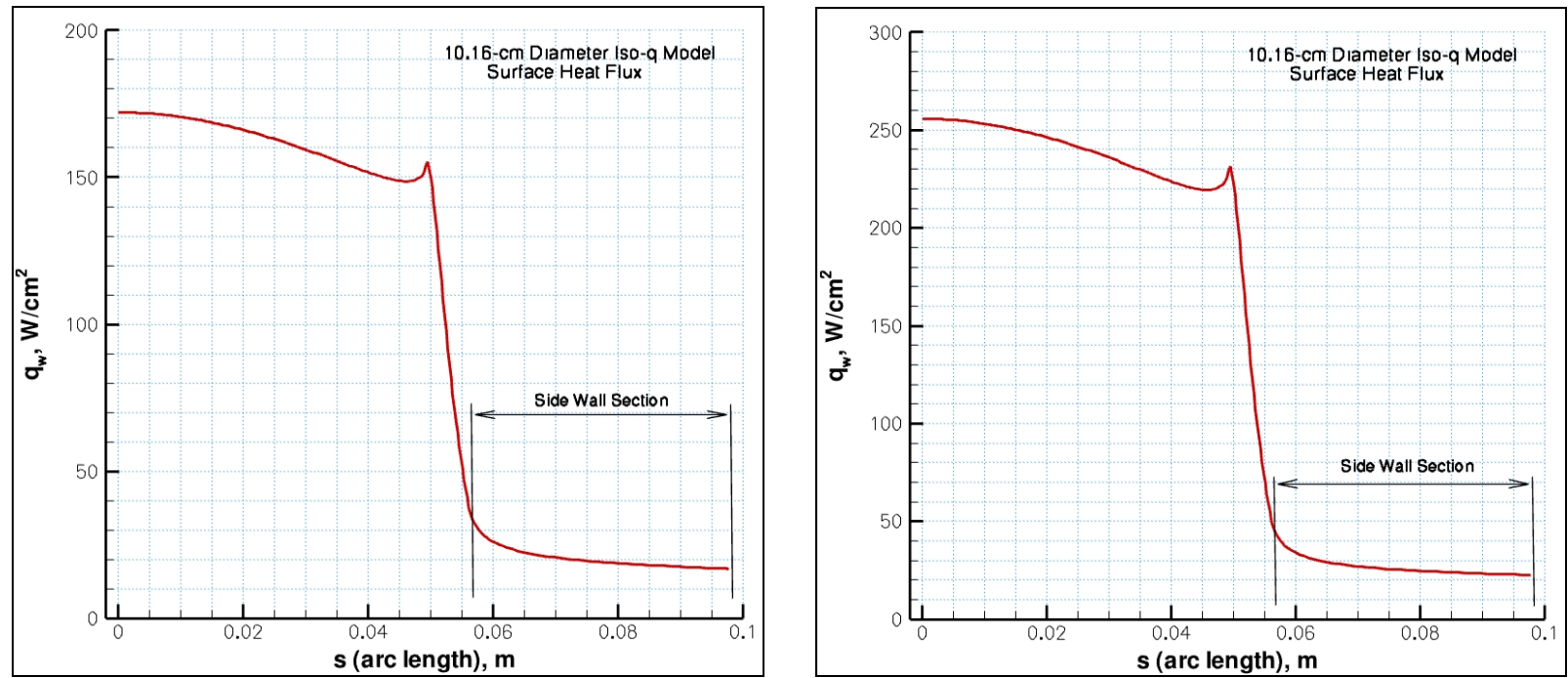

(a) (b)

Figure 13 Heatflux distribution on LI-2200 coupon for the nominal arc-jet test condition. (Tahir Gokcen).

\section{Test Results and Analysis}

The tests were successfully conducted, and we were able to achieve the target heat flux and pressure conditions. LI-2200 coupons with sidewall thermocouples survived heat flux at both temperatures, and no melting or significant distortion of the coupons was observed during the test. Figure $\mathbf{1 4}$ shows the images of one of the LI-2200 coupons before, during, and after the test. From the thermocouple data, it was clear that the RCG coating protected the thermocouples and the coupons. This test was the first of its kind to obtain sidewall temperature on coupons during arc-jet operations. These results are instrumental in developing and validating $2 \mathrm{D}$ and $3 \mathrm{D}$ thermal response models. Figure 15 shows the temperature history obtained from thermocouples and pyrometers on LI-2200 coupons. For the test run at $175 \mathrm{~W} / \mathrm{cm}^{2}$ heat flux, the maximum temperature at the stagnation point reached $1600{ }^{\circ} \mathrm{C}$. Both pyrometer and stagnation point thermocouples showed the same value. The shoulder and sidewall thermocouples showed the temperature rise in the range of $700^{\circ} \mathrm{C}-900^{\circ} \mathrm{C}$. As expected, the closer the thermocouple depth was to the stagnation surface, the higher the temperature was achieved, with the shoulder thermocouple showing the highest value. The sidewall pyrometer showed a temperature rise to $650{ }^{\circ} \mathrm{C}$. Due to a large imaging spot size of the pyrometer $(2.54 \mathrm{~cm}$ diameter), it was hard to define the exact height the data corresponded to. For test run \# 4, the temperature rise up to 
$1700{ }^{\circ} \mathrm{C}$ was recorded by the stagnation point thermocouple. At that point, the thermocouple reached its limit and stopped functioning. Pyrometer data at the stagnation point shows the steady maximum temperature of $1700^{\circ} \mathrm{C}$ at the stagnation surface for the entire heat flux duration. The sidewall and shoulder thermocouples show the temperature rise in the range of $900-1000{ }^{\circ} \mathrm{C}$, respectively. The data reaffirms that there is significant heating at the sidewall and multidimensional effects are significant. Figure $\mathbf{1 6}$ shows the comparison of thermocouple data at the stagnation surface and at the sidewall with CFD predictions using Data Parallel Line Relaxation code ( DPLR) ${ }^{11}$ and 2D thermal response code, TITAN. ${ }^{12}$ While, analytical predictions are in good agreement with thermocouple data at the stagnation point, they over predict the temperature at and near the shoulder region. Further investigations are required to explain the discrepancy.

All the PICA coupons with off-axis and centerline thermocouple plugs also survived the test. No model disintegration or flow of hot gases through the sample was observed during the test. Images of one PICA model instrumented with off-axis thermocouples before, during, and after test run \# 4 are shown in Figure 17. It is clear from the post-test pictures that PICA coupons charred and recessed during the test. Laser scans and manual measurements were performed on the samples to obtain the magnitude of recession and the post-test contours of recessed surfaces. The measurements confirmed that the presence of the off-axis thermocouples and different architecture of the coupons did not affect the overall coupon geometry or the test outcome.

The thermocouple data obtained during this test is shown in Figures 18 and 19. The temperature rise corresponding to $175 \mathrm{~W} / \mathrm{cm}^{2}$ heat flux is shown Figures $18 \mathrm{a}$ and $18 \mathrm{~b}$. At $2.29 \mathrm{~cm}$ height from the stagnation point, the centerline thermocouple shows the temperature rise of $350{ }^{\circ} \mathrm{C}$, whereas the thermocouple closest to the sidewall (at centerline radius of $4.45 \mathrm{~cm}$ ) shows the temperature rise of $950{ }^{\circ} \mathrm{C}$. This is a very significant effect of sidewall heating, coupled with the high in-plane conductivity of PICA. Figure17a also shows that at $2.29 \mathrm{~cm}$ height, as we follow the radius away from the centerline, the temperature is steadily increasing. The thermocouple data is very consistent for both off-axis coupons. Figure 18b shows the comparison of temperature rise between centerline and $4.45 \mathrm{~cm}$ radial location at $3.05 \mathrm{~cm}$ height. The data from three different thermocouples, at $120^{\circ}$ angles apart, are very consistent with each other and confirms the azimuthal symmetry of heat load entering into the coupons. The centerline thermocouple shows the temperature rise of $300^{\circ} \mathrm{C}$, whereas the off-axis thermocouples at $4.45 \mathrm{~cm}_{-}$shows that they reached $700{ }^{\circ} \mathrm{C}$ at the peak value. The analytical predictions from TITAN and comparison to the test data are shown in Figure 19. The TITAN predictions are in excellent agreement with the test data. A discussion of TITAN modeling approach and comparison between 1D FIAT model and TITAN are provided in references 5 and 12. The thermocouple data obtained from run $\# 4\left(250 \mathrm{~W} / \mathrm{cm}^{2}\right.$ flux $)$ is shown in Figures 20a and 20b. The data shows similar trends as the previous test run. The temperature rise at the sidewall thermocouples far exceeds the temperature rise at the centerline. Another interesting observation was that even though the heat loads for the two test conditions were very similar, the temperature rise at the centerline is about $50-100{ }^{\circ} \mathrm{C}$ lower for run \# 4 . However, the sidewall thermocouples show a very similar rise of temperature for both test conditions. The comparison with TITAN data for run \# 4 is shown in Figure 21a and 21b. Again, TITAN predictions are in excellent agreement with test data. Figure 22 shows the recession profile. The coupons maintained the ISO-Q shape during the test.
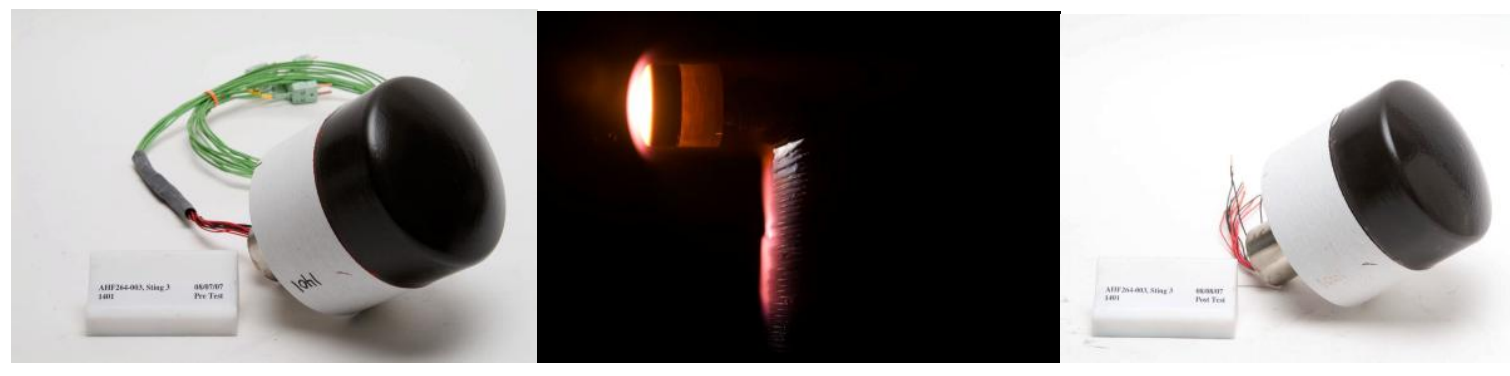

Figure 14. RCG coated LI-2200 coupons before, during and after arcjet test. 

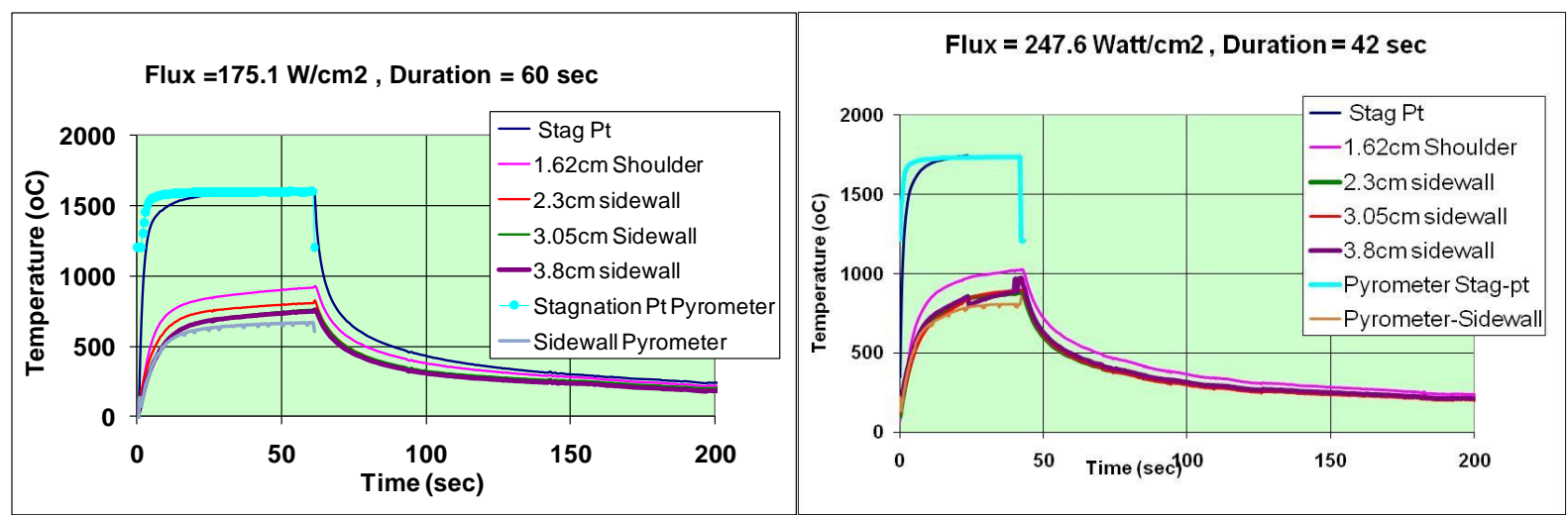

Figure 15. Temperature profile measured on LI-2200 Coupons, a) Run\# 3 b) Run \# 4

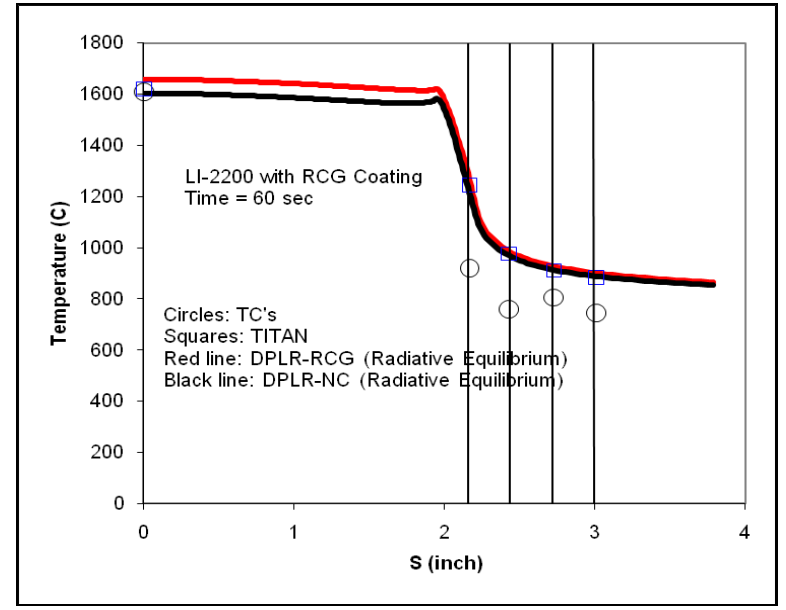

Figure 16.Comparison of sidewall thermocouple data in LI-2200 coupon with analytical models.
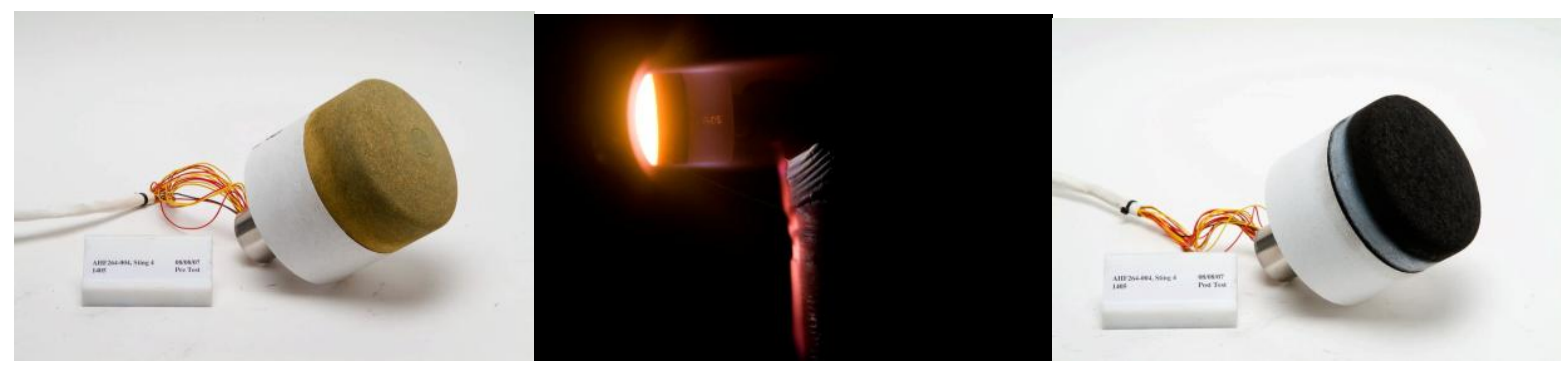

Figure 17. PICA coupon with off-axis thermocouple, before, during and after the arcjet test. 


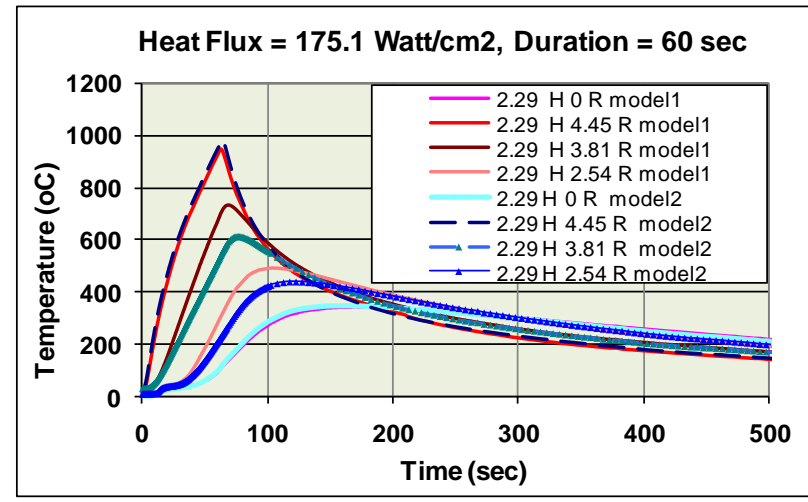

(a) $2.29 \mathrm{~cm}$ depth



(b) $3.05 \mathrm{~cm}$ depth

Figure 18. Temperature profile measured on PICA Coupons from Off-axis thermocouples for Run \# 3.

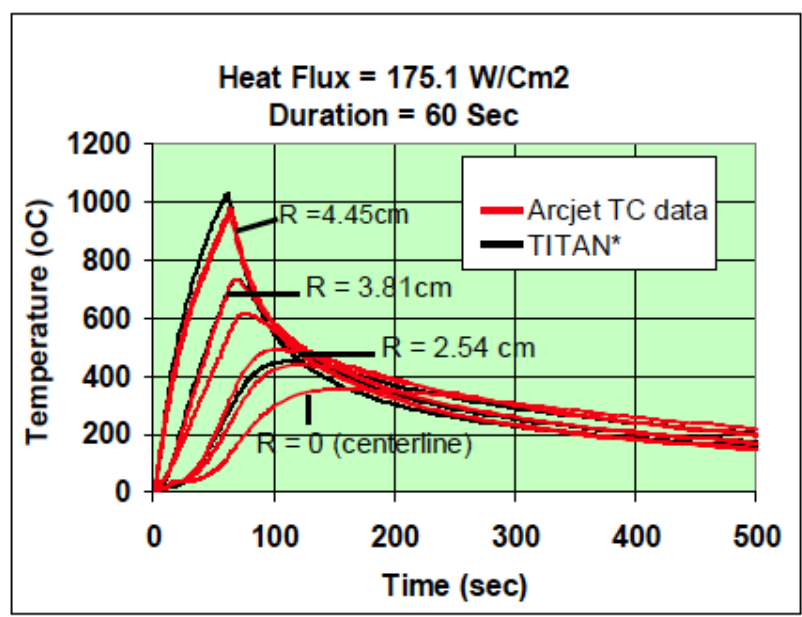

(a) $2.29 \mathrm{~cm}$ depth

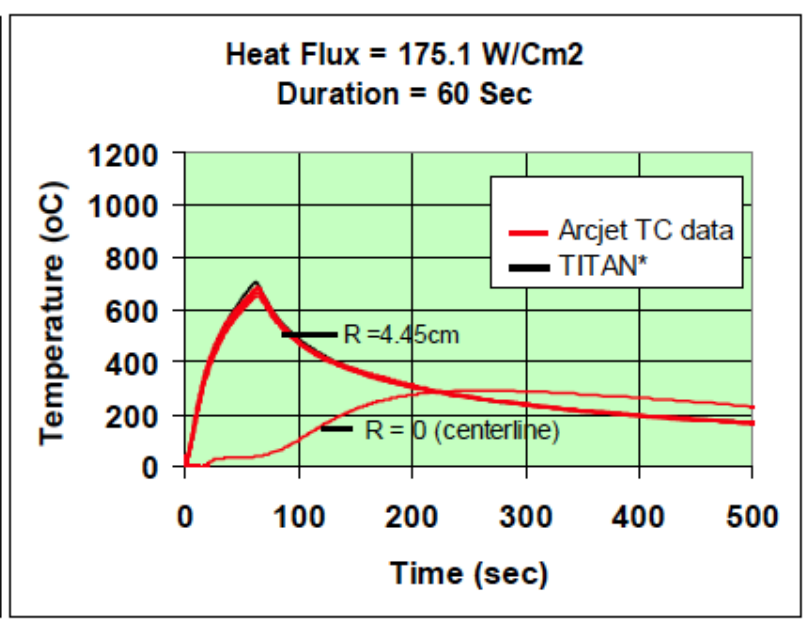

(b) $3.05 \mathrm{~cm}$ depth

Figure 19. Comparison of thermocouple data with TITAN predictions for Run \# 3

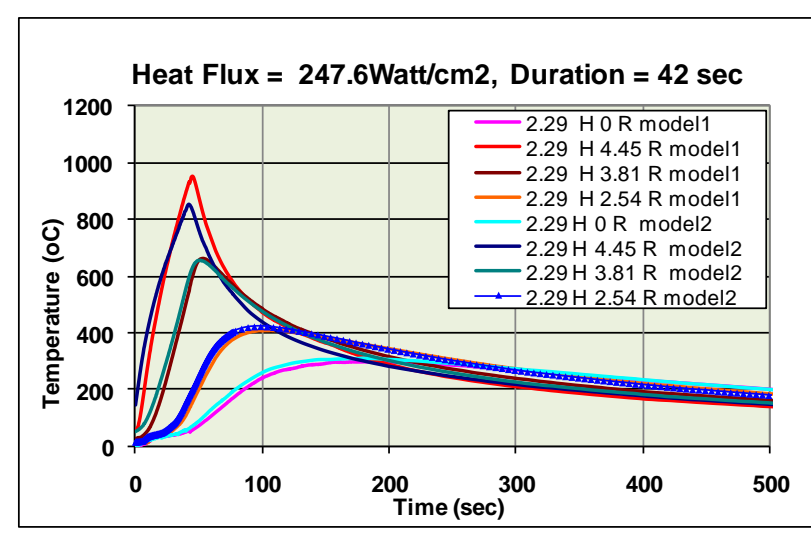

(a) $2.29 \mathrm{~cm}$ depth

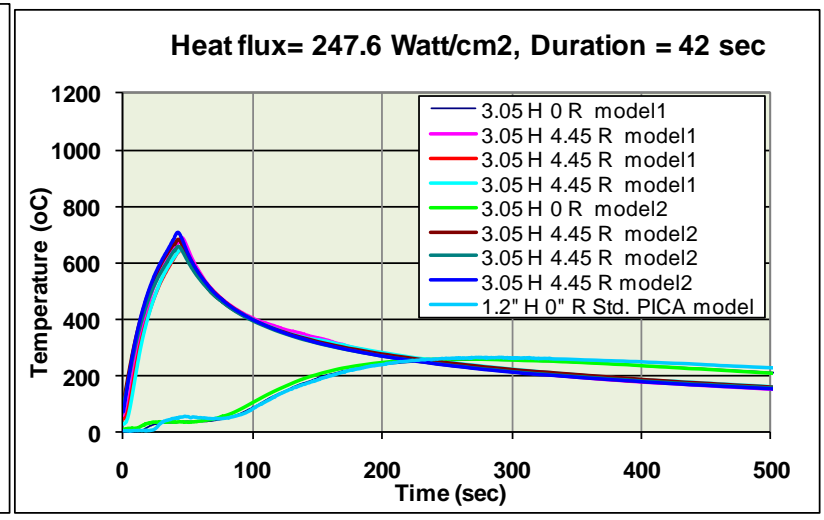

(b) 3.05 cm depth

Figure 20a. Temperature profile measured on PICA Coupons from off-axis thermocouples for Run \# 4 

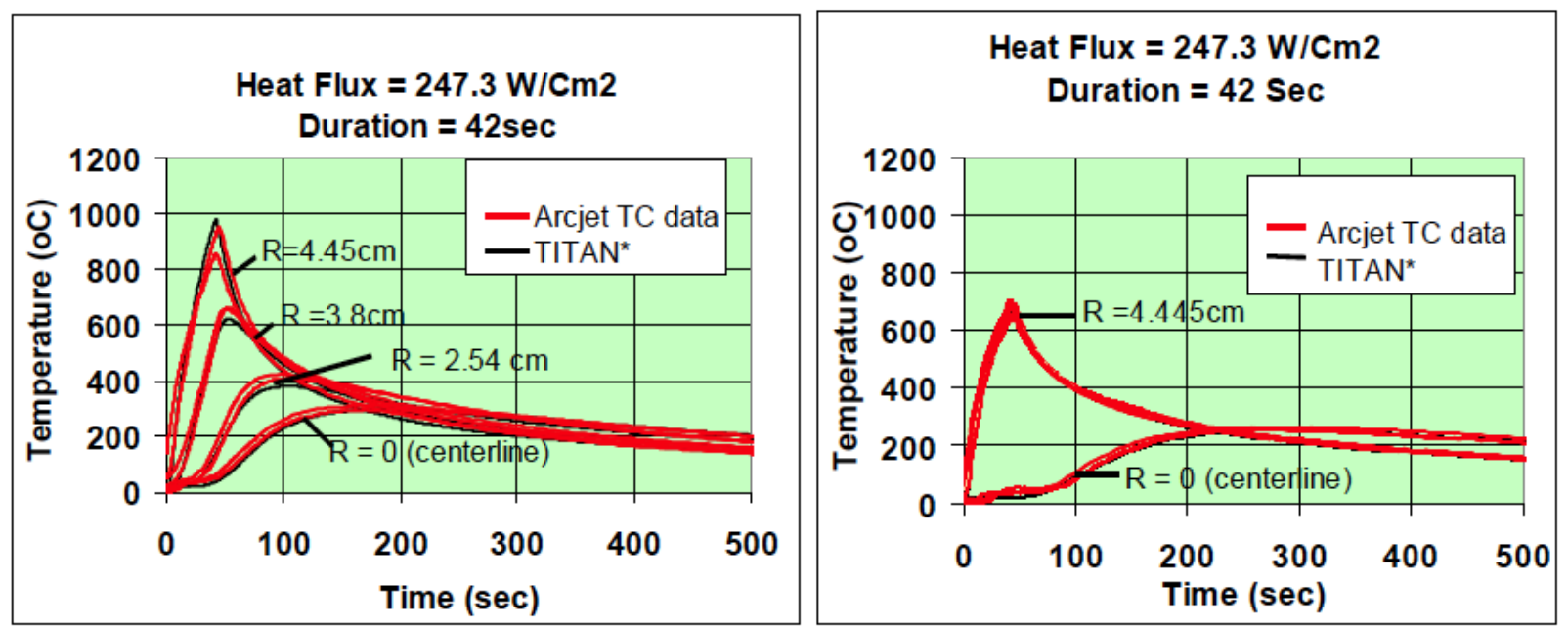

Figure 21. Temperature profile measured on PICA Coupons for Run \# 4.
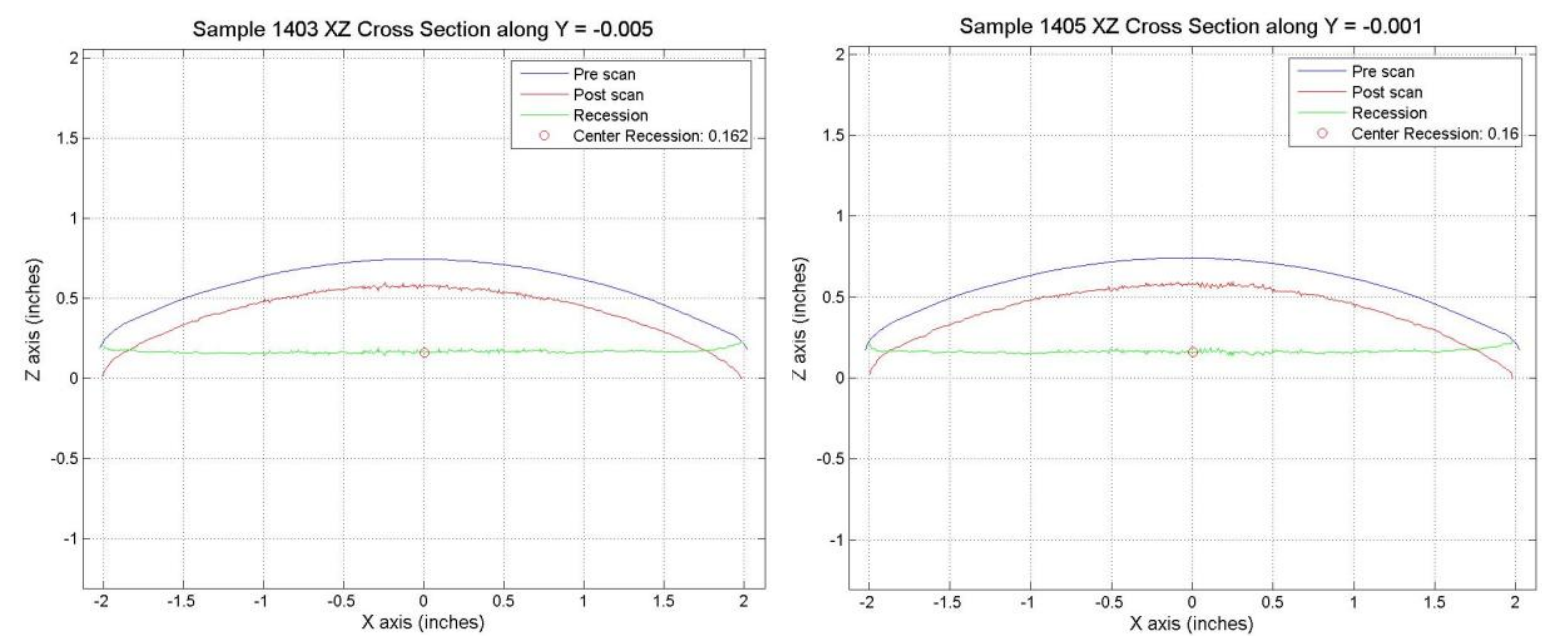

Figure 22. Pre and Post test laser scans to measure stagnation surface recession on PICA coupons.

\section{Conclusions}

The effects of sidewall heating on PICA were successfully demonstrated, first through the analytical model, subsequently followed by arcjet testing. The authors were able to design and fabricate test articles that were instrumented with sidewall and off-axis thermocouples. The test runs were conducted at the Aerodynamic Heating Facility at NASA Ames Research Center. Both PICA and LI-2200 coupons with off-axis thermocouples survived the tests and temperature histories at various radial locations were obtained. The data showed that sidewall heating is significant during the arcjet tests and there is a very high temperature rise due to the sidewall heating when coupled with high in-plane conductivity. The data were later used to compare and validate two-dimensional thermal response code TITAN, developed by scientists at NASA Ames Research Center.

\section{Acknowledgment}

The authors gratefully acknowledge the support provided by the Orion TPS Advanced Development Project specially Ethiraj Venkatapathy and NASA Ames Research Center through their contract to the ELORET Corporation. We also acknowledge the arcjet test facility engineer Frank Hui and NASA-SCAP for their critical 
financial support of the arcjet operational capability at NASA Ames Research Center. We acknowledge Frank Milos for providing TITAN data and Tahir Gokcen for providing CFD results for the arc-jet experiments.

\section{References}

${ }^{1}$ Peterson, A. B., Nichols, F., Mifsud, B., and Love,W., "Arc Jet Testing in NASA Ames Research Center Thermophysics Facilities," AIAA paper 92-5041, Dec. 1992.

${ }^{2}$ Laub, B., Balboni, J. and Goldstein, H., "Ground Test Facilities for TPS Development,” NASA TM-2002-211400, NASA Ames Research Center, Moffett Field, California, May 2002.

${ }^{3}$ Laub, B., "Use of Arc-Jet Facilities in the Design and Development of Thermal Protection Systems", AIAA Paper 2006-3292, 25th AIAA Aerodynamic Measurement Technology and Ground Testing Conference, 5 - 8 June 2006, San Francisco, California.

${ }^{4}$ Chen, Y.-K. and Milos, F.S., “Ablation and Thermal Response Program for Spacecraft Heatshield Analysis,” Paper 98-0273, AIAA 36th Aerospace Sciences Meeting \& Exhibit, Reno, NV, Jan. 12-15, 1998.

${ }^{5}$ Milos, F.S. and Chen, Y.-K., "Ablation and Thermal Response Property Model Validation for Phenolic Impregnated Carbon Ablator", AIAA paper 2009-262, 47th AIAA Aerospace Sciences Meeting Including The New Horizons Forum and Aerospace Exposition, January 2009, Orlando, Florida.

${ }^{6}$ Tran, H., Johnson, C, Rasky, D., Hui, F., Chen, Y.-K., and Hsu, M., "Phenolic Impregnated Carbon Ablators (PICA) for Discovery Class Missions," AIAA Paper 96-1911, June 1996.

${ }^{7}$ Anon., "NASA-Space Shuttle Manual 1988".

${ }^{8}$ Anon., "MSC.Marc User Guide Version 2007".

${ }^{9}$ Milos, F.S., and Chen, Y.-K., "Ablation and Thermal Property Model for Phenolic Impregnated Carbon Ablator (PICA)," NASA/TM-2009-215377, Jan. 2009.

${ }^{10}$ Terrazas-Salinas, I., and Cornelison, C., “Test Planning Guide for ASF Facilities,” Thermophysics Facilities Branch, Space Technology Division, NASA Ames Research Center, March 1999.

${ }^{11}$ Wright M.J., Candler,G.V. and Bose D. "Data-Parallel Line Relaxation Method for the Navier-Stokes Equations" AIAA Journal, Vol. 36, No. 9, 1603-1609.

${ }^{12}$ Milos, F.S. and Chen, Y.-K., "Two-Dimensional Ablation, Thermal Response, and Sizing Program for Pyrolyzing Ablators," Journal of Spacecraft and Rockets, Vol. 46, No. 6, 1089-1099. 